\title{
An Increasing Trend in the Early-Winter Precipitation around Japan and Its Relationship with Enhanced Heating over the Tropical Eastern Indian Ocean
}

\author{
Kazuaki Yasunaga ${ }^{1}$, Atsushi Hamada ${ }^{1}$, and Kazuaki Nishii ${ }^{2}$ \\ ${ }^{1}$ Department of Earth Science, Graduate School of Science and Engineering, University of Toyama, Toyama, Japan \\ ${ }^{2}$ Graduate School of Bioresources, Mie University, Mie, Japan
}

\begin{abstract}
This study examines the factors responsible for the long-term changes of winter monsoonal flow around Japan in association with increasing precipitation trends in December along the coastal areas of Honshu (the main island of Japan) facing the Sea of Japan. The precipitation around the tropical eastern Indian Ocean and maritime continent has significantly increased in recent years. Thus, a packet of the stationary Rossby wave associated with the anomalous heating deflects the subtropical jet to the south over the eastern edge of the Eurasian continent. The deflection of the jet gives favorable conditions for the development of a low pressure trough in the lower level on the eastern side, leading to the formation of negative height anomalies near the surface around Japan.

Although tropical precipitation also increases in November and January, the anomalous heating induces negative height anomalies and cyclonic circulations over the inland region of China and eastern offshore region of Japan (to the further west and east in comparison with those in December) in these months. As a result, monsoonal flow around Japan (and precipitation along the coastal areas of the Sea of Japan) shows no long-term trends in November or January.

(Citation: Yasunaga, K., A. Hamada, and K. Nishii, 2019: An increasing trend in the early-winter precipitation around Japan and its relationship with enhanced heating over the tropical eastern Indian Ocean. SOLA, 15, 238-243, doi:10.2151/sola.2019-043.)
\end{abstract}

\section{Introduction}

Winter monsoon in the vicinity of Japan is characterized by a northwesterly (NW) wind, which is associated with a strong pressure gradient between the cooled continent and warmer ocean (e.g., Fig. 1a). The NW monsoonal flow significantly absorbs sensible and latent heats over the Sea of Japan, where the sea surface temperatures (SSTs) are maintained relatively warm in mid-winter along the Tsushima Current. It eventually brings about enormous amounts of precipitation around the coastal land area of Honshu (the main island of Japan) facing the Sea of Japan (e.g., Fig. 1 in Arai and Yasunaga 2019). Consequently, this region is known to be one of the areas with the heaviest winter precipitation in the world.

Our previous paper (Yasunaga and Tomochika 2017; YT17 hereafter) examined the long-term changes in the monthly precipitation along the coastal areas of the Sea of Japan and discovered that precipitation in December significantly increases by $\sim 50 \%$ of the climatological precipitation in most of the observational stations from the mid-1980s to 2015, while there are no remarkable changes in the precipitation in November or January. Although SST also shows significantly positive trends over the central and southern parts of the Sea of Japan in December of the corresponding period, it was suggested that the intensified monsoonal flow is mainly responsible for the precipitation increase. Thus, the reason for the more intense NW monsoonal flow in December (rather

Corresponding author: Kazuaki Yasunaga, Department of Earth Science, Graduate School of Science and Engineering, University of Toyama, Gofuku 3190, Toyama-city, Toyama 930-8555, Japan. E-mail: yasunaga@ sus.u-toyama.ac.jp.

(C)The Author(s) 2019. This is an open access article published by the Meteorological Society of Japan under a Creative Commons Attribution 4.0 International (CC BY 4.0) license (http://creativecommons.org/license/by/4.0). than November and January) in recent years needs to be considered. Therefore, this paper explores the long-term trends of the large-scale atmospheric pressure pattern leading to the intensified NW monsoon.

\section{Data and methodology}

This study used data obtained from the European Centre for Medium-Range Weather Forecasts interim reanalysis (ERAInterim, herein ERAI) for dynamical and physical variables such as horizontal and vertical winds, geopotential height, and temperature (Dee et al. 2011). The time interval of the dataset is 6 hours, and the horizontal resolution is $0.75^{\circ}$ in both zonal and meridional directions. Moreover, data obtained from the Global Precipitation Climatology Project (GPCP) version 2.3 was used for monthly precipitation estimates, spanning the period from January 1979 to the present (Adler et al. 2018). Besides, outgoing longwave radiation (OLR) data obtained from the polar-orbiting satellites of NOAA was used as a proxy for rainfall (Liebmann and Smith 1996). The horizontal resolutions of GPCP rainfall and OLR are $2.5^{\circ}$.

A simple linear regression analysis was conducted by applying least squares method to the time series of several variables (e.g., monthly mean geopotential height, horizontal wind, precipitation, and OLR) to estimate their linear trends. The statistical significance was tested using a two-sided Student's t test with significance levels of 0.05 and 0.01 . The calculation was performed for the period between 1988 and 2015, following the analysis in YT2017. As a result, the degree of freedom for the regression analysis is estimated to be $26(=28-2)$. In addition, multiple regression analysis was conducted to clarify the linear relationships among positive height anomalies in the pole region, increasing trends of tropical precipitation, and negative height anomalies around Japan.

\section{Results}

Figure $1 \mathrm{~b}$ represents the linear trends of geopotential height and horizontal winds at $1000 \mathrm{hPa}$ level in December. Negative anomalies of geopotential height were observed between the high and low pressure systems over the Eurasian continent and the Bering Sea with the center around the main island of Japan, and the wind anomalies show anti-clockwise circulations over Japan. In wintertime, NW wind prevails (Fig. 1a), and the cyclonic wind anomalies indicate that the monsoonal flow is intensified over the central and western parts of Japan, while it is opposed over the eastern part. YT17 found that the monthly accumulated precipitation amounts significantly increased around the central and western parts of Japan (Fig. 5 of YT17). Thus, the features of Fig.1b are consistent with the results of YT17.

Linear trends of geopotential height and horizontal winds at $850 \mathrm{hPa}, 500 \mathrm{hPa}$, and $300 \mathrm{hPa}$ levels were calculated for more extended areas in order to clarify the factors responsible for the cyclonic anomalies over Japan (the climatological distributions of these variables are represented in S.Fig. 1). Negative anomalies were also observed at the lower level over the Indian subcontinent and the tropical Indian Ocean, while positive anomalies were 

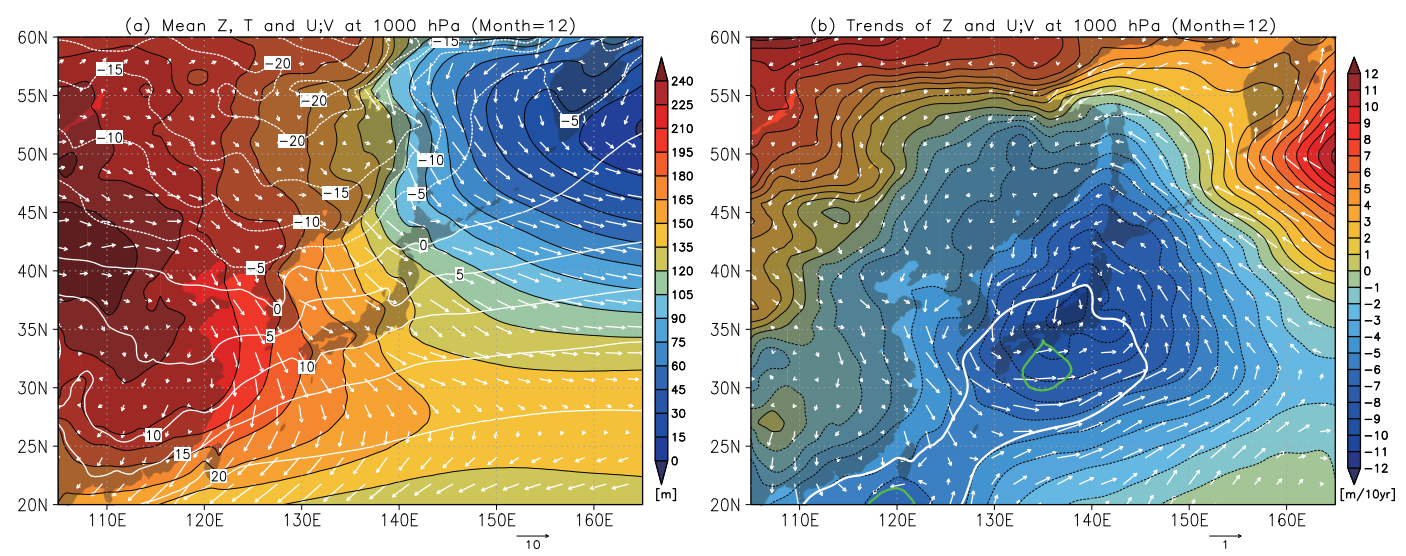

Fig. 1. Geographical distributions of (a) climatological mean geopotential height (shade), temperature (white contour), and horizontal wind (vector); and (b) linear trends of monthly mean geopotential height (shade) and horizontal wind (vector) at $1000 \mathrm{hPa}$ level in December. Climatological mean and linear trends are calculated for the period of 1988-2015. In panel (b), thick white and green lines represent statistically significant changes at $95 \%$ and $99 \%$ levels, respectively; and the linear trends are scaled for the 10-year period (the units are $m$ 10-year ${ }^{-1}$ for geopotential height and $\mathrm{m} \mathrm{s}^{-1} 10$-year ${ }^{-1}$ for horizontal wind).
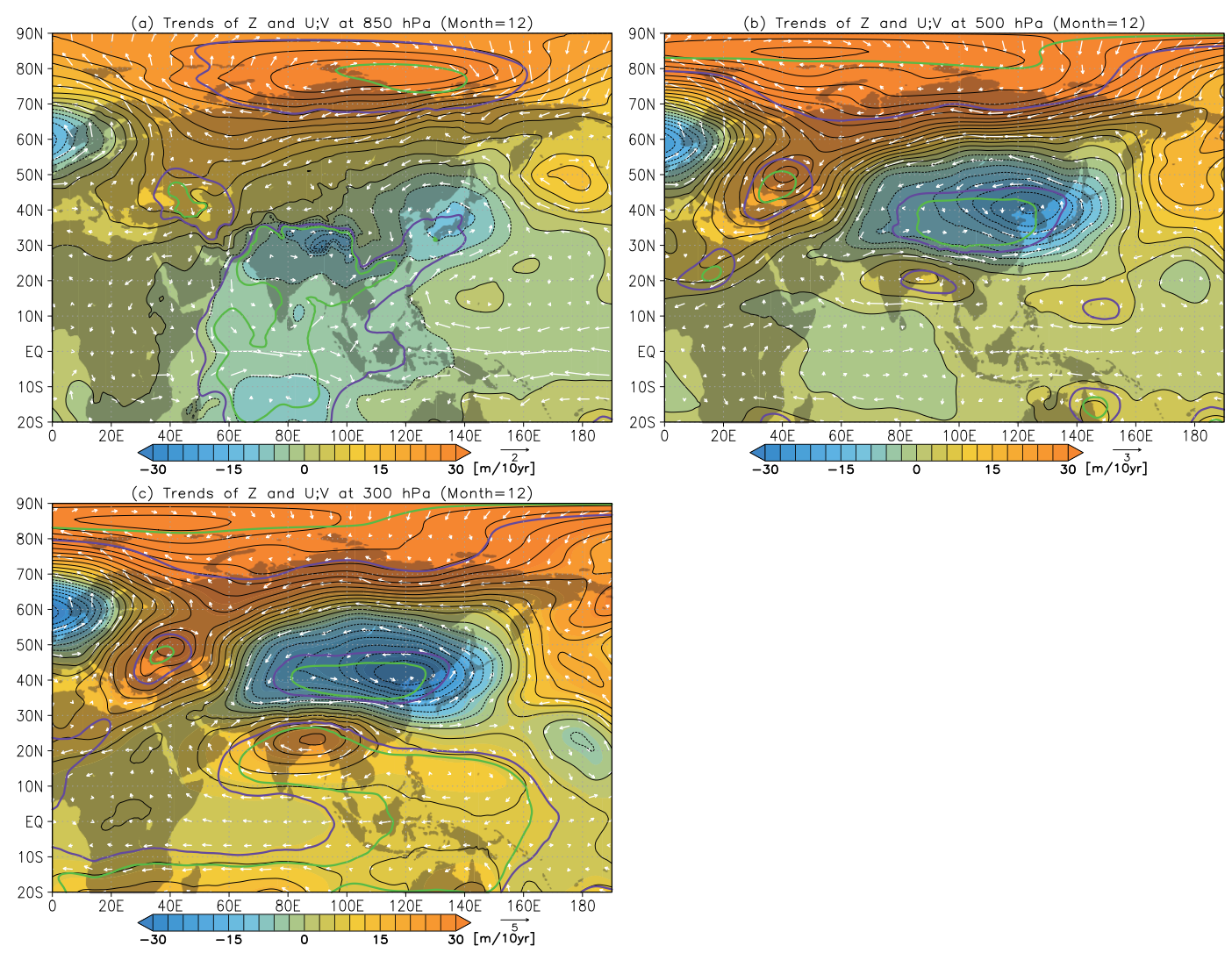

Fig. 2. Linear trends of monthly mean geopotential height (shade) and horizontal wind (vector) at (a) $850 \mathrm{hPa}$ level (b) $500 \mathrm{hPa}$ (c) $300 \mathrm{hPa}$ levels in December. Thick purple and green lines represent statistically significant changes at $95 \%$ and $99 \%$ levels, respectively.

prominent over Siberia and the northern part of Turkey (Fig. 2a). In the mid troposphere, the negative anomalies around Japan extended to the west, and the height anomalies over the Indian subcontinent was slightly positive (Fig. 2b). In addition, positive anomalies were more significant over West Asia and the pole region. The basic features in the upper level were similar to those in the mid-troposphere, where negative height anomalies were located around East Asia including Japan and positive anomalies were observed over West Asia and the pole region (Fig. 2c). It should be also noted that positive anomalies around the Indian subcontinent were more prominent in the upper level than at the mid-level, indicating that the height anomalies had baroclinic structures.

Significantly positive anomalies of geopotential height and anticyclonic wind anomalies which were situated across the Indian subcontinent, Indian Ocean, and maritime continent (Fig. 2) are similar to the heat-induced tropical circulation (Matsuno 1966; Gill 1980). Some previous studies have clarified that winter precipitation in Japan is closely related to the enhanced tropical convection. For example, Inaba and Kodera (2010) compared 

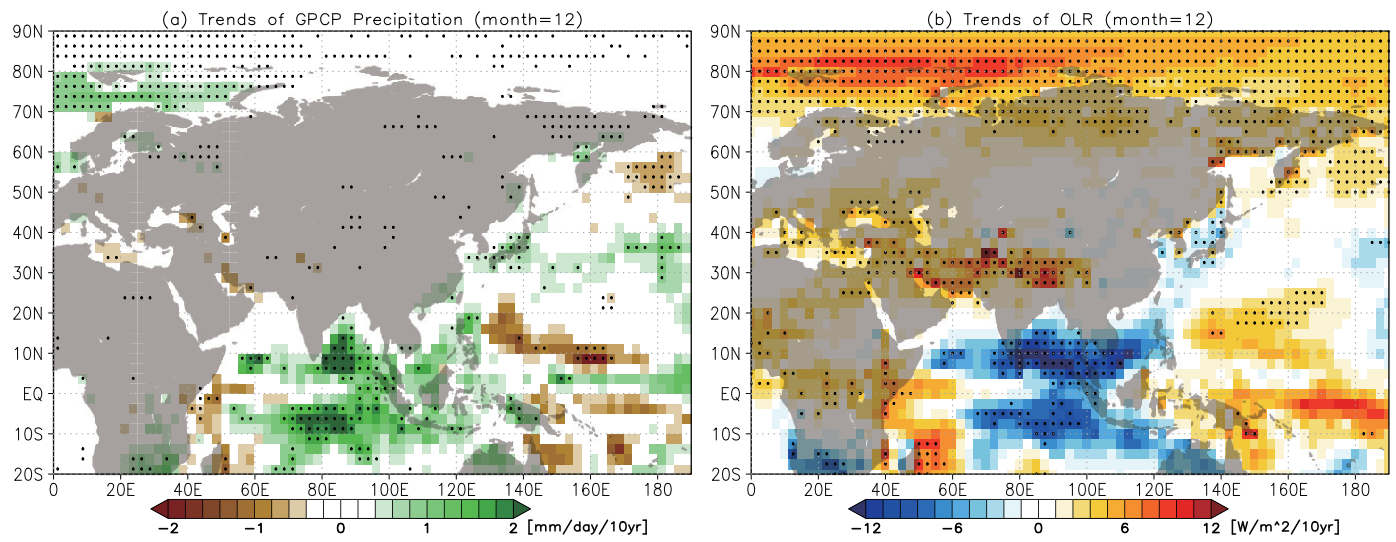

Fig. 3. Geographical distributions of linear trends (1988-2015) of (a) monthly mean precipitation intensity and (b) OLR. The stippling indicates regions that exceed the $95 \%$ statistical significance level. The linear trends are scaled for the 10 -year period (the units are mm $10-$ year ${ }^{-1}$ and $\mathrm{W} \mathrm{m}^{-2} 10-$ year ${ }^{-1}$ ).

successful and unsuccessful ensemble forecasts and found that intense convection over the Bay of Bengal and South China Sea contributed to unusually heavy snowfall and low temperatures in Japan in December 2005. Ueda et al. (2015) conducted numerical experiments using a linear baroclinic model and concluded that the intensified convection over the maritime continents and the neighboring oceans is primarily responsible for cyclonic circulation around Japan. Yamazaki et al. (2019) further demostrated that particular types of the snowfall distribution over Japan accompany the intensification of convection there. These studies are the motivation behind this study to further examine the trends of precipitation and OLR in the tropics.

Figure 3a represents the linear trends of the monthly mean precipitation. As expected, significantly positive anomalies of precipitation extended over the eastern Indian Ocean and maritime continent. The increasing rate normalized by the climatological monthly precipitation amount (S.Fig. 2) is $\sim 15-18 \%$ per decade. Moreover, OLR anomalies were negative in the corresponding region (Fig. 3b), which confirms the more vigorous activity of tropical convection in recent years.

Based on the results of the present analysis and previous studies, increasing precipitation over the eastern Indian Ocean and maritime continent in recent years have intensified positive geopotential anomalies over the Indian subcontinent through Matsuno-Gill response. Besides, a packet of stationary Rossby waves emitted from the positive anomalies over the Indian subcontinent caused negative height anomalies over East Asia in the upper level (Fig. 2c). This is confirmed by north-eastward wave activity flux (WAF), which was introduced by Takaya and Nakamura (2001), from the Indian continent to East Asia in the upper level (Fig. 4). On the other hand, WAF does not show any significat signals in the middle or lower troposphere, although simple correlation analysis reveals that timeseries of precipitation in the tropics are closely related to height anomalies in the lower levels around Japan (not shown).

The negative anomalies over East Asia in the upper level induces the advection of warmer air on the eastern side, and accompanies negative height anomalies in the lower level around Japan (e.g., Figs. 1b and 2a), which indicates that the phase of the cyclonic anomaly tilts to the west as the height increases. The westward tilting structure like a baroclinic wave is also found in the "western Pacific pattern" (Tanaka et al. 2016), which is one of dominant teleconnection patterns over the North Pacific (Wallace and Gutzler 1981). Based on the results obtained by Tanaka et al. (2016), this phase tilting in Fig. 2 would suggest that the cyclonic anomaly develops and is maintained through baroclinic conversion of available potential energy from the climatological mean fields that have large meridional temperature gradient over the region. This speculation basically follows the previous investigations and is not unique in the present study. Especially, Ueda et al.

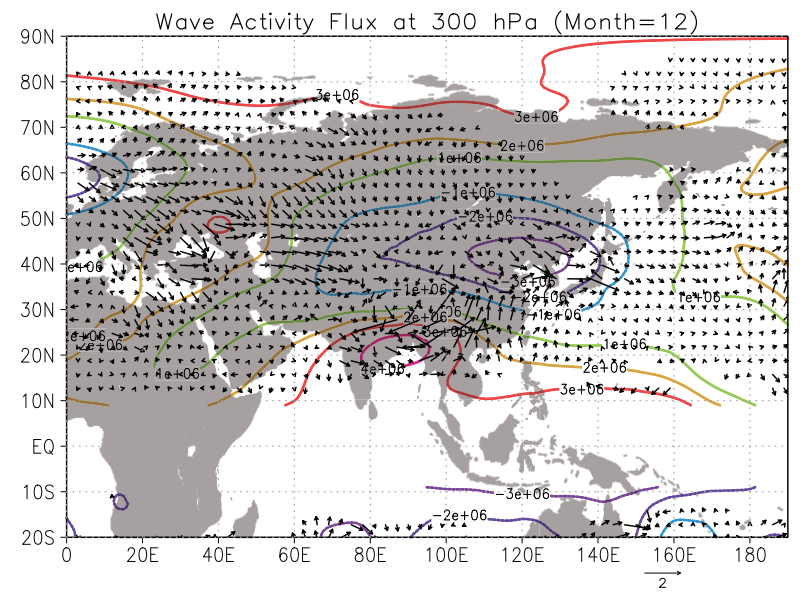

Fig. 4. Geographical distributions of stream functions and wave activity fluxes at $300-\mathrm{hPa}$ level, which are calculated using the anomalies of the geopotential height and horizontal winds in Fig. 2c.

(2015) examined the heat-induced response in a linear baroclinic model under the wintertime atmospheric circulation, and indicated that the intensified convection over the maritime continents and the neighboring oceans lead to anti-cyclonic circulation over the Asian continent and subsequent anomalous cyclonic circulation around Japan. However, gradual changes of the responses on the sub-monthly time-scale and detailed mechanisms for the maintenance should be clarified in the future study.

\section{Discussion}

In the previous section, the long-term changes of pressure patterns around Japan and adjacent areas were shown as well as their relationships with the precipitation over the tropical eastern Indian Ocean. On the other hand, several issues are still left unsolved, which includes 1) the impact of the positive anomalies of geopotential height in the pole region (e.g., Fig. 2), 2) the reason why the NW monsoonal flow does not change in November or January. These are briefly addressed in the present section.

\subsection{Influence of the positive anomalies of geopotential height in the pole region}

The recent global warming in association with the reduction of the Arctic sea ice in the pole region may affect the East Asian winter monsoon (e.g., Honda et al. 2009). Thus, multiple 

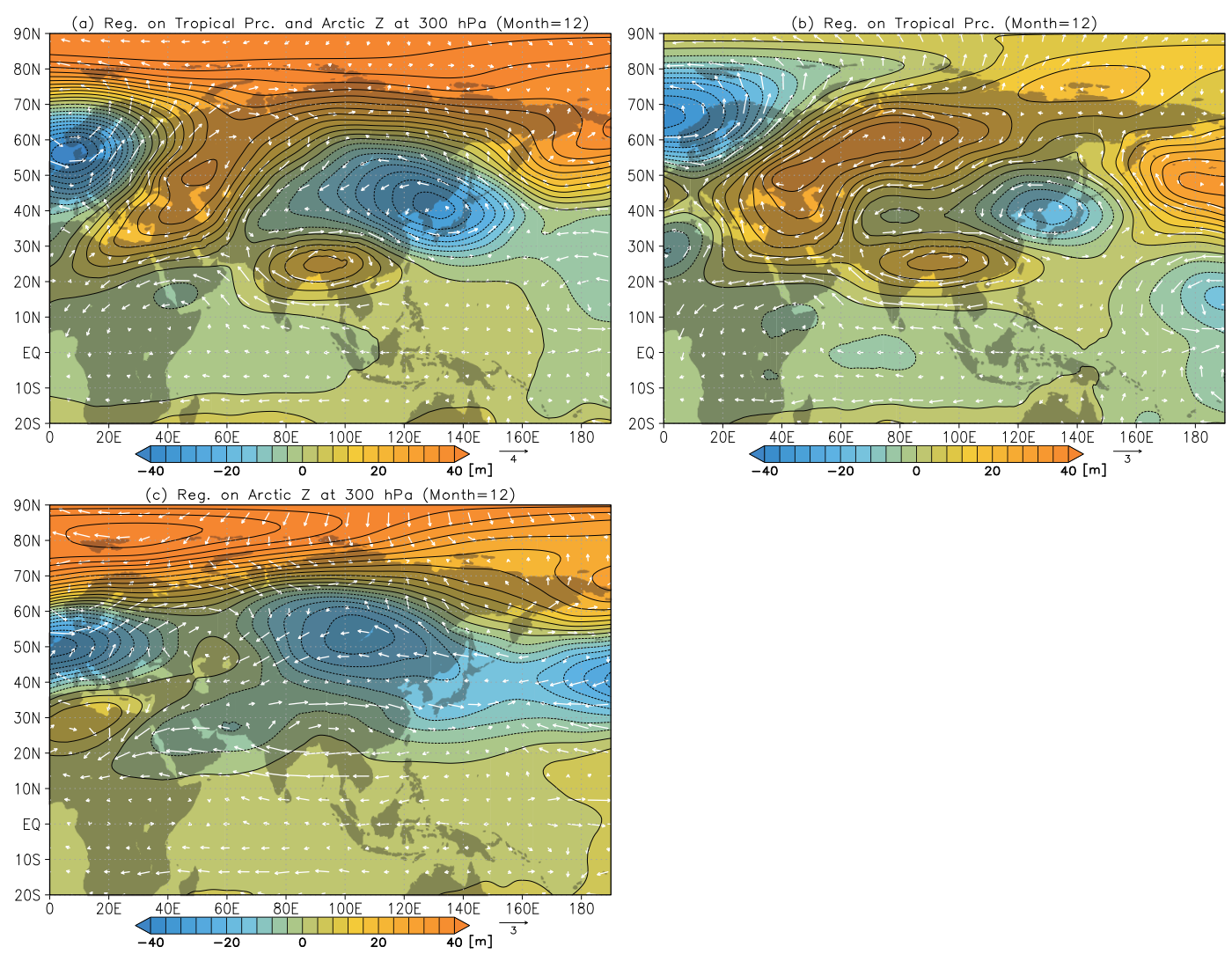

Fig. 5. (a) Geographical distributions of 300-hPa geopotential height and horizontal winds regressed against the precipitation over the Eastern Indian Ocean and maritime continent and 300-hPa geopotential height averaged over the pole region (See text for further details). The same fields partially regressed against the former component (precipitation over the Eastern Indian Ocean and maritime continent) and the latter component (300-hPa geopotential height averaged over the pole region) are represented in panels (b) and (c), respectively. Anomalies are all scaled for the 10-year period (the units are $m$ 10-year ${ }^{-1}$ for geopotential height and $\mathrm{m} \mathrm{s}^{-1}$ 10-year ${ }^{-1}$ for horizontal wind).

regression analysis was performed on geopotential height and horizontal winds at $300 \mathrm{hPa}$ level, using $300-\mathrm{hPa}$ geopotential height averaged over the pole region $\left(40^{\circ} \mathrm{W}-100^{\circ} \mathrm{E}, 80^{\circ} \mathrm{N}-90^{\circ} \mathrm{N}\right)$ and precipitation over the eastern Indian Ocean and maritime continent $\left(80^{\circ} \mathrm{E}-120^{\circ} \mathrm{E}, 15^{\circ} \mathrm{S}-15^{\circ} \mathrm{N}\right)$ as independent variables (different latitude and longitude selections do not affect the results much). The regressed fields reproduced the patterns of the height anomaly and corresponding wind fields (Fig. 2c), although negative height anomaly was slightly extended to the north-western direction (Fig. 5a). When the regressed fields were decomposed into each component, the corresponding anomalies had distinctive characteristics (Figs. 5b and 5c): zonal-symmetric patterns were prominent in the field partially regressed to height anomaly in the pole region, while stationary wave trains were evident in the field partially regressed to the tropical convection. In terms of the negative anomaly of geopotential height and cyclonic circulations over Japan and its west-side region, meanwhile, the contributions of tropical convection were larger.

There are numerous investigations on the relationships between East Asian winter monsoon climate and low-frequency variability in extratropical oscillations such as Arctic oscillation (AO) (e.g., Gong and Ho 2004) and North Atlantic Oscillation (NAO) (e.g., Watanabe 2004). However, none of them show significant trends in the present analysis period (not shown). In contrast, the geopotential height shows positive trends over the pole region in the resent years (Fig. 2), which would be associated with the recent Arctic amplification (Screen and Simmonds 2010). These results justify the reason why AO or NAO index was not employed in the present analysis.

\subsection{Trends of geopotential height in November and January}

In November, precipitation over the tropical Indian Ocean shows remarkably increasing trends (Figs. 6a and 6b), and significant positive anomalies of geopotential height similar to MatsunoGill response are located in the upper level (Figs. 7a and 7b). However, the center of the positive height anomaly over the Indian subcontinent slightly shifts to the west with smaller amplitude, in comparison with those in December. The WAF indicates that a packet of stationary Rossby waves propagates to the north rather than to the north-east (S.Fig. 4a), probably reflecting the location of the positive height anomaly and the relatively weak jet stream. As a result, negative height anomalies developed over inland region of China and did not extend to Japan (Figs. 7a and 7b).

In January, precipitation trends are negative over the tropical Indian Ocean and positive trends are discovered over the western Pacific (Figs. 6c and 6d). The WAF indicates that a packet of stationary Rossby waves propagates to the further east (S.Fig. 4b) in association with the eastward shift of the heat source, resulting in the positive and negative anomalies of geopotential height over China and the eastern offshore region of Japan, respectively (Figs. $7 \mathrm{c}$ and $7 \mathrm{~d}$ ).

\section{Summary}

In this study, the factors responsible for the long-term changes of the monsoonal flow around Japan were examined in association with increasing trends of precipitation in December along the coastal areas of the Sea of Japan. The results indicate that precipitation around the tropical eastern Indian Ocean and maritime continent have significantly increased in recent years. It was 

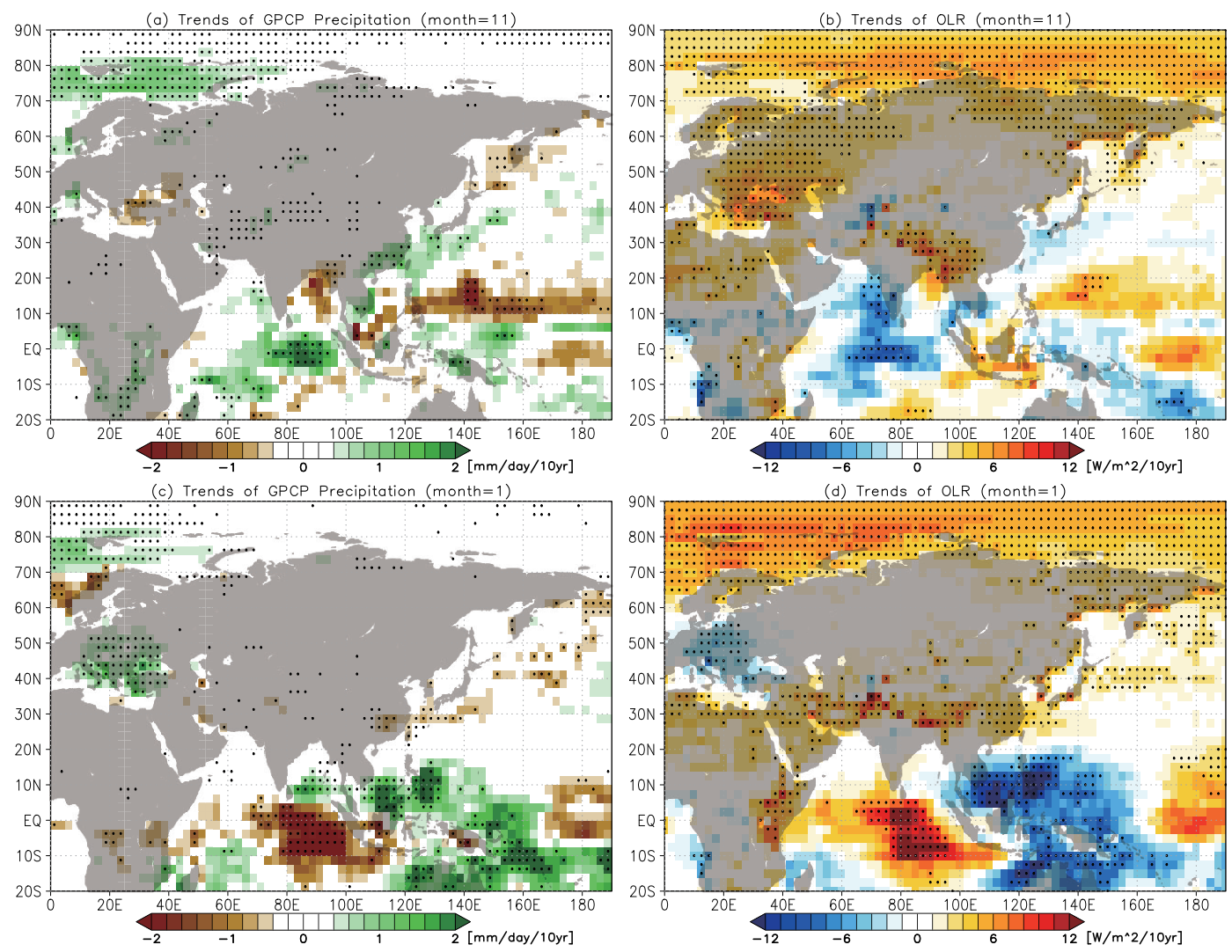

Fig. 6. Geographical distributions of linear trends (1988-2015) of monthly mean precipitation intensity and OLR in November (a and b) and those in January (c and d). The stippling indicates regions that exceed the $95 \%$ statistical significance level. The linear trends are scaled for the 10 -year period (the units are $\mathrm{mm} 10-$ year $^{-1}$ and $\mathrm{Wm}^{-2} 10-$ year $\left.{ }^{-1}\right)$.
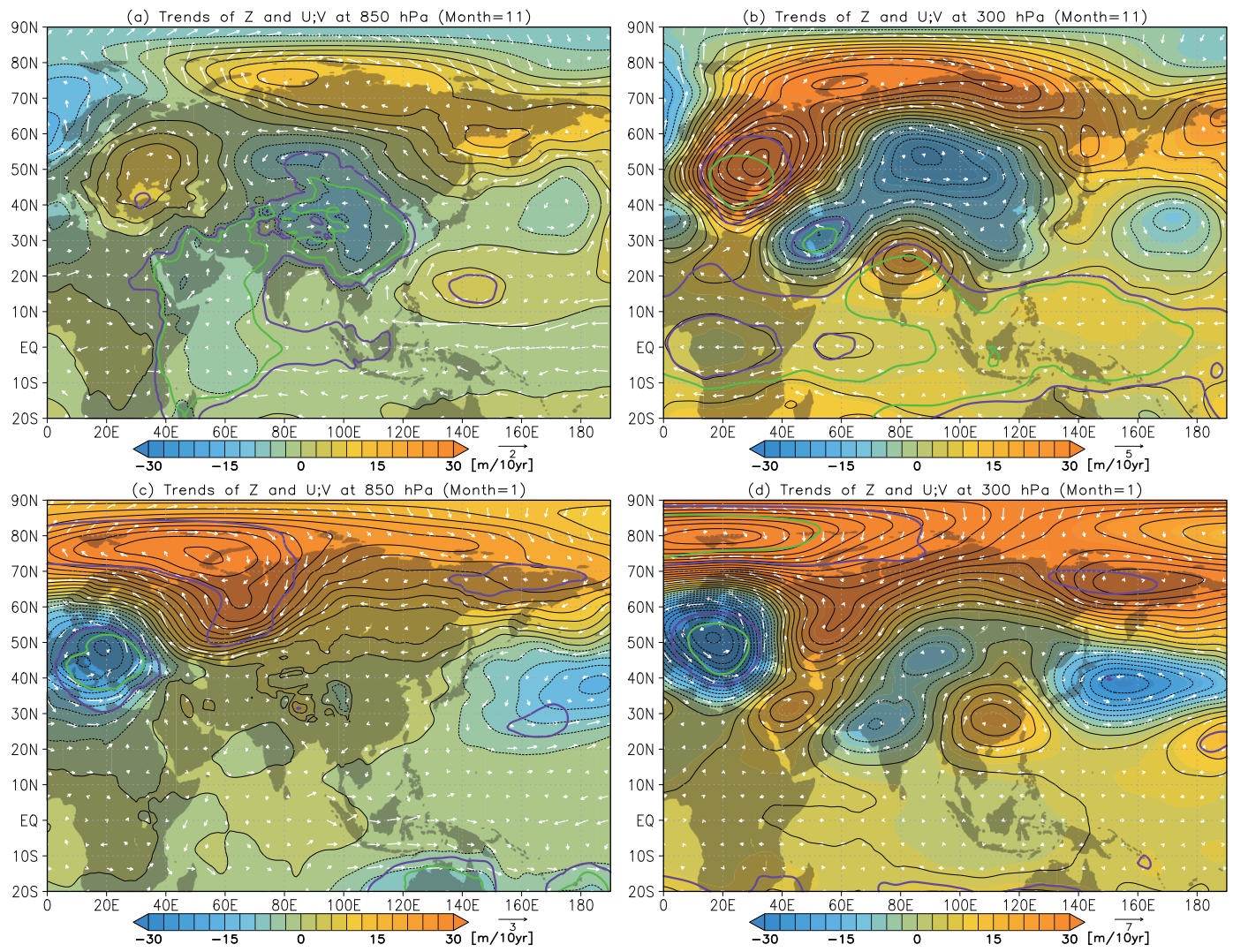

Fig. 7. Linear trends of monthly mean geopotential height (shade) and horizontal wind (vector) at $850 \mathrm{hPa}$ and $300 \mathrm{hPa}$ levels in November (a and d) and those in January ( $\mathrm{c}$ and d). Thick purple and green lines represent statistically significant changes at $95 \%$ and $99 \%$ levels, respectively. 
also revealed that a packet of the stationary Rossby wave associated with the anomalous heating deflects the subtropical jet to the south over the eastern edge of the Eurasian continent. This deflection gives favorable conditions for the development of a low pressure trough in the lower level on the eastern side and would lead to the formation of negative height anomalies near the surface around Japan. Close relationships between tropical convection and pressure patterns around Japan have been well recognized in previous works. However, the present study is the first to clarify their relationships from the point of view of long-term trends.

Geopotential height shows positive trends in the pole region, which may also affect the increasing trend of precipitation. Based on multiple regression analysis, however, tropical convection was found to be primarily essential to the formation of the negative height anomalies in the lower level around Japan. Although tropical precipitation increases in November and January, the anomalous heating is located to the west and east in comparison with that in December. Reflecting the different location of the hating, negative height anomalies and cyclonic circulations are induced in the upper level over the inland region of China and eastern offshore region of Japan in November and January, respectively. As a result, monsoonal flow around Japan (and precipitation along the coastal areas of the Sea of Japan) shows no long-term trends in these months.

It is beyond the scope of this study to clarify why precipitation in December significantly increases over the eastern Indian Ocean and maritime continent. However, the positive trend of tropical precipitation might be related to a packet of the stationary Rossby wave from the further west (around the northern part of Turkey). In fact, WAF indicates that a packet of stationary Rossby wave propagates to the east and then deflected to the south, thereby intensifying the positive anomalies over the Indian subcontinent, as seen in Fig. 4. Similar features were also reported by Sakai and Kawamura (2009) and Inaba and Kodera (2010). On the other hand, Sakai and Kawamura (2009) suggested that La Niña-like SST patterns influence East Asian winter monsoon through the intensification of convective activity over the maritime continent. We will examine the importance of the SST and remote forcing to the enhanced convection over the eastern Indian Ocean and maritime continent in the future study.

\section{Acknowledgments}

Helpful comments from anonymous reviewers are gratefully acknowledged. This work was supported by JSPS KAKENHI Grants JP25400463, JP16KK0095, JP19H05697, and JP19H05702, and Environment Research and Technology Development fund (2-1904) of the Environmental Restoration and Conservation Agency of Japan.

Edited by: M. Nonaka

\section{References}

Adler, F. R., and co-authors, 2018: The global precipitation climatology project (GPCP) monthly analysis (New Version 2.3) and a review of 2017 global precipitation. Atmosphere, 9, 138, doi:10.3390/atmos9040138.

Arai, K., and K. Yasunaga, 2019: Spatial patterns of winter precipitation in the north-central region (Hokuriku District) of Japan. SOLA, 15, 80-86, doi:10.2151/sola.2019-016.

Dee, D. P., and co-authors, 2011: The ERA-Interim reanalysis: Configuration and performance of the data assimilation system. Quart. J. Roy. Meteor. Soc., 137, 553-597, doi: 10.1002/qj.828.

Gill, A. E., 1980: Some simple solutions for heat-induced tropical circulation. Quart. J. Roy. Meteor. Soc., 106, 447-462, doi: 10.1002/qj.49710644905.

Gong, D.-Y., and C.-H. Ho, 2004: Intra-seasonal variability of wintertime temperature over East Asia. Int. J. Climatol., 24, 131-144, doi:10.1002/joc. 1006.

Honda, M., J. Inoue, and S. Yamane, 2009: Influence of low Arctic sea-ice minima on anomalously cold Eurasian winters. Geophys. Res. Lett., 36, doi:10.1029/2008GL037079.

Inaba, M., and K. Kodera, 2010: Forecast study of the cold December of 2005 in Japan: Role of Rossby waves and tropical convection. J. Meteor. Soc. Japan. Ser. II, 88, 719735, doi:10.2151/jmsj.2010-405.

Liebmann, B., and C. A. Smith, 1996: Description of a complete (interpolated) outgoing longwave radiation dataset. Bull. Amer. Meteor. Soc., 77, 1275-1277.

Matsuno, T., 1966: Quasi-geostrophic motions in the equatorial area. J. Meteor. Soc. Japan, 44, 25-43, doi:10.2151/jmsj1965. 44.125.

Nishimoto, E., and S. Yoden, 2017: Influence of the stratospheric quasi-biennial oscillation on the Madden-Julian oscillation during Austral summer. J. Atmos. Sci., 74, 1105-1125, doi: 10.1175/JAS-D-16-0205.1.

Sakai, K., and R. Kawamura, 2009: Remote response of the East Asian winter monsoon to tropical forcing related to El NiñoSouthern Oscillation. J. Geophys. Res. Atmos., 114, doi: 10.1029/2008JD010824.

Screen, J. A., and I. Simmonds, 2010: The central role of diminishing sea ice in recent Arctic temperature amplification. Nature, 464, 1334, doi:10.1038/nature09051.

Son, S.-W., Y. Lim, C. Yoo, H. H. Hendon, and J. Kim, 2016: Stratospheric control of the Madden-Julian oscillation. $J$. Climate, 30, 1909-1922, doi:10.1175/JCLI-D-16-0620.1.

Takaya, K., and H. Nakamura, 2001: A formulation of a phaseindependent wave-activity flux for stationary and migratory quasigeostrophic eddies on a zonally varying basic flow. $J$. Atmos. Sci., 58, 608-627, doi:10.1175/1520-0469(2001)058 $<0608$ :AFOAPI $>2.0$. CO; 2 .

Tanaka, S., K. Nishii, and H. Nakamura, 2016: Vertical structure and energetics of the Western Pacific teleconnection pattern. J. Climate, 29, 6597-6616, doi:10.1175/JCLI-D-15-0549.1.

Ueda, H., A. Kibe, M. Saitoh, and T. Inoue, 2015: Snowfall variations in Japan and its linkage with tropical forcing. Int. J. Climatol., 35, 991-998, doi:10.1002/joc.4032.

Wallace, J. M., and D. S. Gutzler, 1981: Teleconnections in the geopotential height field during the northern hemisphere winter. Mon. Wea. Rev., 109, 784-812, doi:10.1175/15200493(1981)109<0784:TITGHF>2.0.CO;2.

Watanabe, M., 2004: Asian jet waveguide and a downstream extension of the North Atlantic Oscillation. J. Climate, 17, 4674-4691, doi:10.1175/JCLI-3228.1.

Yamazaki, A., M. Honda, and H. Kawase, 2019: Regional snowfall distributions in a Japan-Sea side area of Japan associated with jet variability and blocking. J. Meteor. Soc. Japan. Ser. II, 97, 205-226, doi:10.2151/jmsj.2019-012.

Yasunaga, K., and M. Tomochika, 2017: An increasing trend in the early winter precipitation during recent decades along the coastal areas of the Sea of Japan. J. Hydrometeor., 18, 2893-2906, doi:10.1175/JHM-D-17-0105.1.

Zhang, C., and J. Ling, 2011: Potential vorticity of the MaddenJulian Oscillation. J. Atmos. Sci., 69, 65-78, doi:10.1175/ JAS-D-11-081.1.

Manuscript received 4 September 2019, accepted 29 October 2019 SOLA: https://www.jstage.jst.go.jp/browse/sola/ 